OPEN ACCESS

Edited by:

Tassula Proikas-Cezanne, University of Tübingen, Germany

Reviewed by:

Ying Zhu,

Sun Yat-sen University, China Yan Wu,

Sun Yat-sen University, China

${ }^{*}$ Correspondence:

Leopold Eckhart

leopold.eckhar@meduniwien.ac.at

Specialty section:

This article was submitted to

Cell Death and Survival,

a section of the journal

Frontiers in Cell and Developmental

Biology

Received: 30 April 2019

Accepted: 11 July 2019

Published: 30 July 2019

Citation:

Eckhart L, Tschachler E and Gruber F (2019) Autophagic Control of Skin Aging.

Front. Cell Dev. Biol. 7:143. doi: 10.3389/fcell.2019.00143

\section{Autophagic Control of Skin Aging}

\author{
Leopold Eckhart ${ }^{1 *}$, Erwin Tschachler ${ }^{1}$ and Florian Gruber ${ }^{1,2}$ \\ ${ }^{1}$ Research Division of Biology and Pathobiology of the Skin, Department of Dermatology, Medical University of Vienna, \\ Vienna, Austria, ${ }^{2}$ Christian Doppler Laboratory for Biotechnology of Skin Aging, Vienna, Austria
}

The skin forms the barrier to the environment. Maintenance of this barrier during aging requires orchestrated responses to variable types of stress, the continuous renewal of the epithelial compartment, and the homeostasis of long-lived cell types. Recent experimental evidence suggests that autophagy is critically involved in skin homeostasis and skin aging is associated with and partially caused by defects of autophagy. In the outer skin epithelium, autophagy is constitutively active during cornification of keratinocytes and increases the resistance to environmental stress. Experimental suppression of autophagy in the absence of stress is tolerated by the rapidly renewing epidermal epithelium, whereas long-lived skin cells such as melanocytes, Merkel cells and secretory cells of sweat glands depend on autophagy for cellular homeostasis and normal execution of their functions during aging. Yet other important roles of autophagy have been identified in the dermis where senescence of mesenchymal cells and alterations of the extracellular matrix (ECM) are hallmarks of aging. Here, we review the evidence for cell type-specific roles of autophagy in the skin and their differential contributions to aging.

Keywords: skin, autophagy, aging, epidermis, keratinocytes, hair, sweat gland, melanocytes

\section{INTRODUCTION}

Changes of the skin belong to the most recognizable signs of aging. Accordingly, skin aging is a major area of interest for cosmetic and skin care industries. From the medical viewpoint, aging of the skin is associated with health problems including increased skin fragility, delayed wound healing and the increased occurrence of skin cancers, the most abundant types of malignancies in humans. The prevention and management of skin aging depends on a thorough understanding of the aging process in general, which can be defined as the time-dependent decline in tissue and organismal functions (Leidal et al., 2018), and on the understanding of the function and interplay of the unique cell types that build the skin. For a long time it has been recognized that the rate of skin aging is determined by intrinsic and extrinsic drivers, but only recent advances in skin gerontology have helped to dissect the molecular and cellular processes that underlie the aging of the skin (Gilchrest and Krutmann, 2006; Chang, 2016; Ghosh and Capell, 2016; Botchkarev, 2017; Rinnerthaler and Richter, 2018; Wang and Dreesen, 2018). Several of the aging processes are triggered or enhanced by the presence of damaged molecules and organelles within cells, and their turnover is controlled partly by autophagy. Besides proteostasis and organelle maintenance, other factors that are accepted hallmarks of aging (López-Otín et al., 2013), such as nutrient sensing and genomic instability are under the control of or elicit the activation of autophagy, making autophagy a major counter-regulatory process that supports skin homeostasis and healthy aging. 
Autophagy is a process of cellular self-digestion by delivering cytoplasmic material to the lysosome for breakdown. Three pathways of autophagy can be distinguished mechanistically, i.e., macroautophagy, microautophagy, and chaperone-mediated autophagy. Macroautophagy is controlled by autophagy-related proteins (ATGs) and depends on the sequestration of material within double-membraned vesicles (autophagosomes) in the cytoplasm. These vesicles fuse with lysosomes to form autophagolysosomes in which the cargo is degraded by lysosomal enzymes. Breakdown products are released from lysosomes and subsequently are utilized for catabolic processes or energy production. Microautophagy is characterized by the invagination of the lysosomal membrane in yeast, whereas in mammals it involves the invagination of the late endosomal membrane to trap cytoplasmic material which is then degraded either in late endosomes or in lysosomes after endosomal-lysosomal fusion (Tekirdag and Cuervo, 2018). Chaperone-mediated autophagy relies on the cytosolic chaperone hsc70 for substrate targeting to the lysosome. Proteins that contain a consensus pentapeptide motif are bound by hsc70, unfolded and translocated into the lysosomal lumen in a lysosome-associated membrane protein type 2A (LAMP2A)-dependent manner (Tekirdag and Cuervo, 2018). For further details of the mechanisms of autophagy, the reader is referred to many excellent reviews (Rubinsztein et al., 2011; Boya et al., 2013; Galluzzi et al., 2017; Hansen et al., 2018; Levine and Kroemer, 2019). In the present review of autophagy in the skin, the term "autophagy" is equivalent to "macroautophagy" unless stated otherwise.

Here, we review the features of skin aging at the levels of the tissue and the cells and then describe the contributions of autophagy to the control of skin aging. We propose a concept in which aging is driven by changes in three categories of cells with different dependencies on autophagy.

\section{SKIN AGING AT THE TISSUE LEVEL}

The skin is a composite organ consisting of a layer of subcutaneous fat tissue, the mesenchymal dermis and the outermost epithelial layer, the epidermis (McGrath, 2005). In addition, there are skin appendages, i.e., hair, sebaceous glands, sweat glands and nails, which are derived through the differentiation of epithelial cells in cooperation with mesenchymal cells. These skin appendages are anchored mainly within the dermis (McGrath, 2005; Figure 1, left panel).

The subcutaneous fat tissue functions both as insulation against temperature fluctuations and as energy storage, and is composed mostly of lobules of adipocytes which are surrounded by a lattice of collagen septae and blood vessels. It provides the link of the skin with the underlying muscles and fasciae. The dermis consists mostly of extracellular matrix (ECM) with collagen, elastin, and glycosaminoglycans as the principal components, all of which are produced by fibroblasts, the most abundant cell type within the dermis. The dermal ECM provides the skin with both strong mechanical resistance and elasticity (Bruckner-Tuderman, 2012). Embedded into the dermis are networks of blood and lymphatic vessels, which supply oxygen and nutrients to the skin, regulate the body temperature, and serve as highways for immune cell trafficking. The vast web of dermal nerve endings reaches as far as into the epidermis and transmits sensorial perceptions such as temperature, touch, pain and itch to the central nervous system (McGlone and Reilly, 2010). Adding to the complexity of this tissue, it harbors a multitude of resident immune cells including mast cells, tissue macrophages and professional antigen presenting cells (McGrath, 2005).

Attached to the dermis by specialized proteins of the basement membrane, the epidermis forms the outermost skin layer. It is a stratified epithelium consisting mainly (95\% of all epidermal cells) of keratinocytes, which undergo terminal differentiation and form the stratum corneum, which serves as the ultimate barrier against the environment (Eckhart and Zeeuwen, 2018). Besides keratinocytes, the epidermis contains regularly dispersed Langerhans cells, the remotest antigen presenting cells of the immune system, and melanocytes, which produce the UV protective melanin and transfer it to the adjacent keratinocytes thereby determining also the color of the skin and hair (McGrath, 2005).

In contrast to internal organs, the signs of skin aging are immediately recognizable also to non-medically trained observers. Most obvious are the occurrence of facial wrinkles which are either the consequence of repeated activity of the underlying muscles during facial expression, or tissue slackening as a consequence of loss of elastin and collagen fibers. Tissue slackening manifests with a loss of the facial oval and sagging of the upper eyelids. In addition, pigment irregularities of sunexposed skin are a hallmark of aging skin (Guinot et al., 2002).

When analyzing skin aging, one has to take into account that apart from intrinsic aging which proceeds in all organs and is genetically determined, skin aging is also strongly modified by extrinsic factors such as chronic sun exposure and life style habits in particular cigarette smoking (Guinot et al., 2002). Intrinsic aging is characterized primarily by a progressive loss of skin tissue, i.e., a thinning of all skin layers. The subcutaneous fat pad decreases with age and so do the components of the dermal ECM. Functionally, the loss of the fat pad results in an increased sensitivity to both hot and cold temperature whereas the loss of the dermal ECM makes the skin more fragile and prone to wounding. Within the epidermis the turnover of keratinocytes is reduced resulting in a thinning of the epidermis and a reduced capacity to rapidly restore the skin barrier after barrier breaks. As to the skin appendages, hair becomes thinner and on the scalp terminal hair follicles are gradually miniaturized (Fernandez-Flores et al., 2019). Most obvious, the natural hair color is lost due to a reduced transfer of pigment from follicular melanocytes to hair keratinocytes and air inclusions into the hair shaft (Fernandez-Flores et al., 2019). Sebum production decreases with age in particular in women after menopause. Similarly, sweat secretion decreases with aging (Dufour and Candas, 2007). Furthermore, chronic pruritus or itch is common problem in the elderly, indicating an age-related conversion of touch to itch sensation due to loss or defects of Merkel cells (Feng et al., 2018).

In contrast to intrinsic or chronological aging, photoaging concerns only body regions which are chronically exposed to 


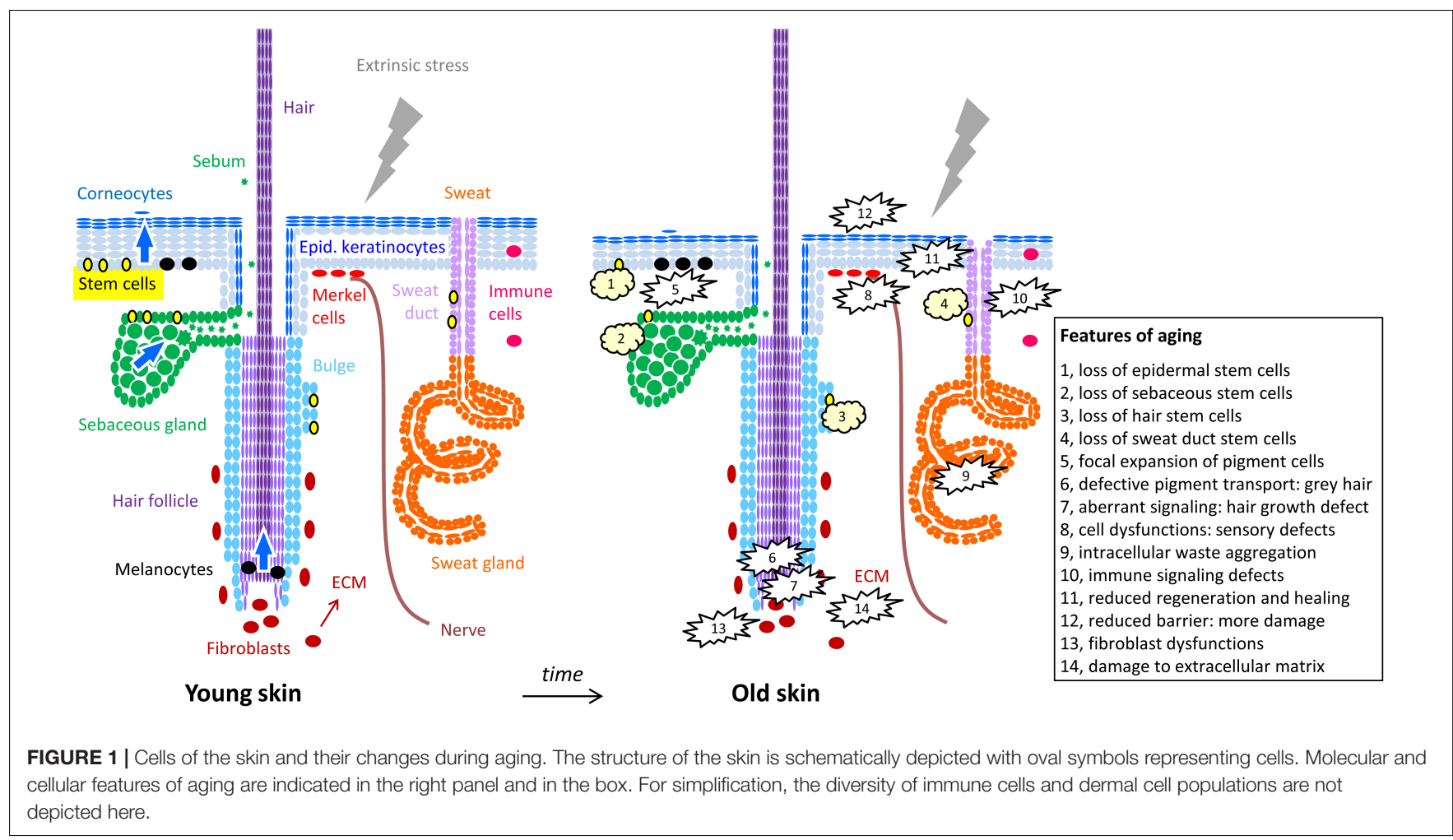

sunlight or to artificial sources of ultraviolet (UV) radiation (Kligman and Balin, 1989; Yaar and Gilchrest, 1998; Gilchrest, 2013). The difference between intrinsic aging and photoaging can most easily be observed in a given individual when comparing UV-exposed skin sites such as the outer forearm to non-exposed sites such as the inner upper arm. Whereas intrinsic aging is characterized by a loss of ECM, photoaged skin contains abundant elastin and collagen fibers, however, they are not arranged like in non-exposed skin but are fragmented and disorganized due to the action of UV-induced proteases (Gilchrest, 2013). In fact the appearance of photoaged skin has been likened to scar tissue (Fisher et al., 1997). In addition, photoaged skin displays very distinct pigment irregularities referred to as age spots and, on the histological level, immune cell infiltrates including mast cells, resulting in a subclinical chronic inflammation. At the molecular level, UVsignature mutations can be detected mainly in keratinocytes and melanocytes long before they become clinically relevant by causing actinic keratoses, basal cell carcinomas or melanomas (Jonason et al., 1996).

\section{SKIN AGING AT THE CELLULAR LEVEL: STEM CELLS, SHORT-LIVED EPITHELIAL CELLS AND LONG-LIVED DIFFERENTIATED CELLS}

Aging is a complex phenomenon which includes many effects at the systemic level but also critical changes at the level of isolated system components such as DNA, cells, and tissues. Here, we put forward the hypothesis that drivers of aging mediate their effects differentially on the various types of cells in the skin and perhaps also in other tissues. We propose to distinguish three categories of cells that change during aging in different ways (Figure 2).

First, stem cells have a long lifetime and relatively low metabolic activity. Within the epidermis the stem cells themselves do not directly contribute to the epidermal barrier, but they give rise to differentiating daughter cells that achieve this function. A decline in the number and activity of stem cells is both driver and marker of skin aging. Of note, epithelial structures with a high cell turnover, such as epidermal keratinocytes strongly depend on stem cells during homeostasis whereas other skin compartments require stem cells predominantly or only during wound repair.

Second, there are cell types that differentiate and undergo fast turnover when they fulfill their function. The metabolic activity of these cells is very high. Examples for this category are epithelial cells of the interfollicular epidermis, sebaceous glands, hair follicles, and the duct of the sweat gland. The maintenance of function of these differentiating cells requires their continuous derivation from stem cells.

Third, differentiated skin cells of diverse developmental histories fulfill specific functions over prolonged periods of time or even during the entire life of an organism. Typically, these cells have significant metabolic activity over long times. Examples of this cell category are neurons, melanocytes, Merkel cells, secretory cells of sweat glands, and fibroblasts. 
Stem cells: Long-lived,

- Epidermal keratinocyte stem cells

- Hair follicle stem cells

- Sebaceous gland stem cells

- Sweat gland duct stem cells low metabolic activity
Short-lived, differentiating cells, high metabolic activity

- Keratinocytes (interfollicular)

- Hair follicle keratinocytes

- Sebocytes

- Sweat gland duct
Long-lived differentiated cells, high metabolic activity

- Merkel cells

- Secretory sweat gland cells

- Melanocytes

- Neurons

- Fibroblasts

- Langerhans cells

\section{Cell-specific functions}

- Sacrifice of cells

- Protection of tissue

- Capacity to regenerate

\section{Autophagy}

Removal of damaged cell components

- Reduction of cytotoxic stress

- Reduction of genotoxic stress

\section{Aging}

- Cell damage and limits of replication

- Decrease in number and regeneration capacity of stem cells

- Alterations of intercellular signals

\section{Autophagy}

Contributions to differentiation

- Breakdown of non-cytoskeletal proteins during cornification

- Lysosomal quality control in holocrine sebocytes
- Response to environment

- Protection of tissue

\section{Autophagy}

Removal of damaged cell components and cell-specific roles

- Reduction of cytotoxic stress

- Intracellular organelle movement

- Pigmentation homeostasis

\section{Aging}

- Cell damage and decline of autophagy

- Malfunction and loss of function

- Cell death (+ inflammation)

- Alterations of intercellular signals


\section{Skin aging / disease}

FIGURE 2 | Three categories of cells play different autophagy-dependent roles in skin aging. We propose that the aging of the skin is driven by changes in the distinct types of skin cells that we categorize according to lifetime (inversely correlated to turnover) and differentiation (execution of specific function within the tissue context). The main roles of autophagy and aging-associated changes are summarized for each cell category.

\section{SKIN AGING AT THE CELLULAR LEVEL: DIFFERENTIAL ROLES OF AUTOPHAGY IN THREE CATEGORIES OF CELLS}

The skin provides several examples to illustrate the two main interactions between autophagy and aging: (1) Autophagy decreases the rate of aging and (2) the activity of autophagy declines during aging. Autophagy suppresses aging in a cellautonomous manner by maintaining intracellular homeostasis and in a non-autonomous manner by contributing to various cell features that protect other cells. For instance, autophagy supports the differentiation of epithelial cells which allows them to protect other cells against external noxae (Velarde, 2017). Since autophagy achieves the removal and recycling of intracellular material only to a certain extent, potential toxic cell components and dysfunctional lysosomes tend to accumulate during the lifetime of cells. Some of the compromised cells succumb to cell death whereas others remain alive but lose their capacity to execute intracellular processes, including autophagy, with full efficiency. Loss and dysfunction of cells manifest in aging.
Autophagy was reported to play various roles in the homeostasis and stress response of skin cells that were reviewed previously (Sukseree et al., 2013a; Sil et al., 2018). Most recently, the roles of autophagy in immune cells of the skin were characterized (Das et al., 2019). For the main types of skin cells, the roles of autophagy and their relevance for aging will be discussed below. According to the above categorization of skin cells, autophagy has different sensitivities to aging-associated processes and different roles in driving processes that enhance skin aging (Figure 2).

(1) Long-lived and mostly quiescent stem cells require autophagy for intracellular homeostasis and for continuous ability to supply functional progeny cells (García-Prat et al., 2016; Boya et al., 2018). Inherent decline or exogenous suppression of autophagy leads to stem cell loss by competition, differentiation, or cell death (Figure 3).

(2) In short-lived differentiating cells, autophagy also contributes to intracellular homeostasis, however, autophagic activity needs to be maintained only over 


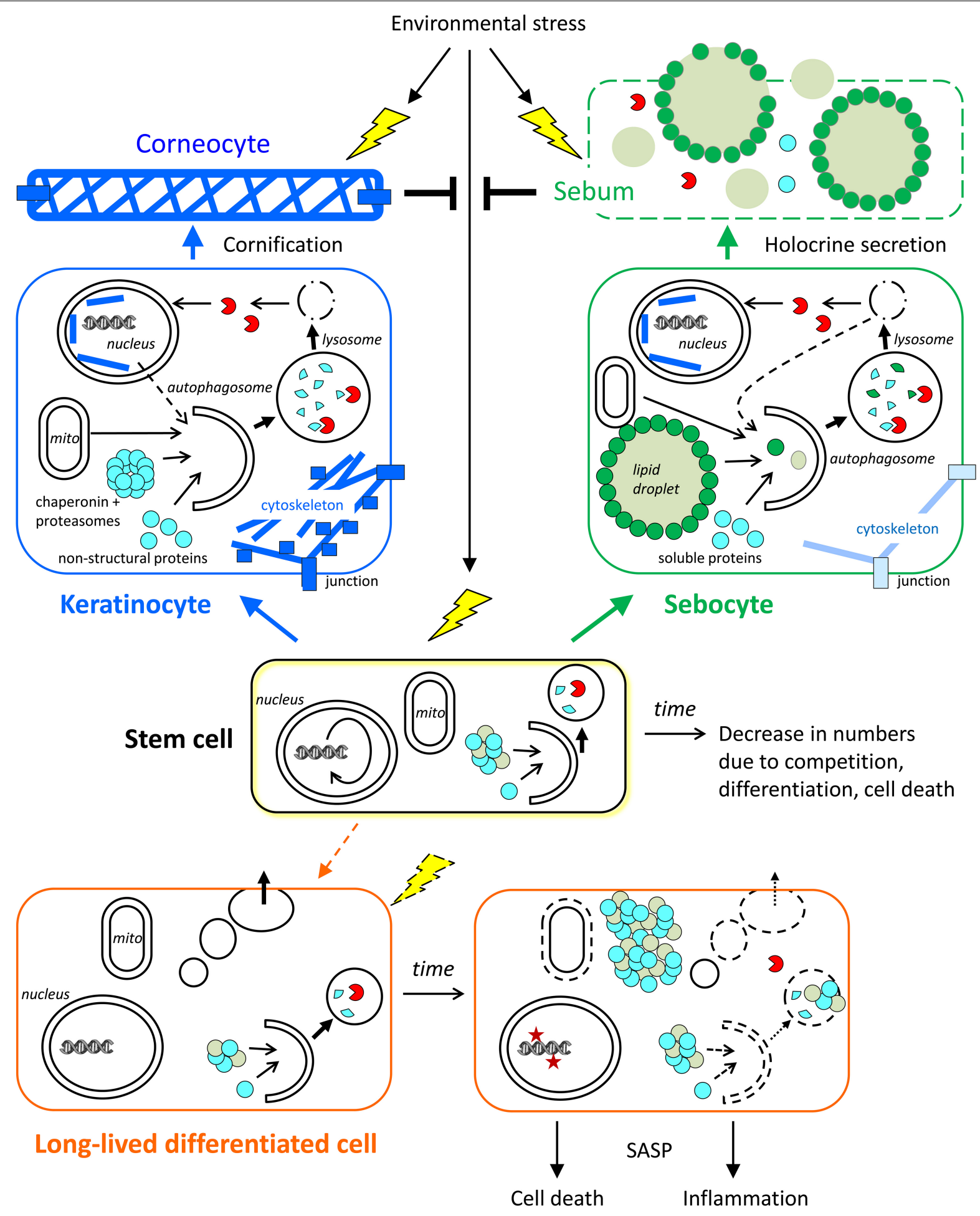

FIGURE 3 | Roles of autophagy in skin cells. The contributions of autophagy to cornification, holocrine secretion, and homeostasis of stem cells and long-lived differentiated cells (exemplified by a sweat gland secretory cell) are schematically shown. Time-dependent changes, such as a decline of autophagy, affect mainly stem cells and long-lived differentiated cells. Short-lived keratinocytes and sebocytes are continuously generated from stem cells and then differentiate rapidly. Autophagy contributes to the formation of corneocytes and sebum, which protect the living cells of the skin against stress factors from the environment. The conversion of stem cells into (short-lived) differentiating keratinocytes and sebocytes occurs throughout life while the conversion of stem cells into long-lived differentiated secretory cells occurs rarely in adult life. Note that specialized stem cells exist in the interfollicular epidermis and in skin appendages whereas only one stem cell is shown in this simplified schematic drawing. 
a short time for these cells to be functional. External and internal factors have little time to impair autophagy during differentiation and consequently an aging-associated decline of autophagy is less likely to occur in these cells. Nevertheless, autophagy defects can be inherited from the long-lived precursor cells (stem cells) and potentially compromise processes such as the defense against microbes, the release of cytokines, and most importantly, the protection against stress factors from the environment (Figure 3).

(3) In long-lived differentiated cells, autophagy contributes to the maintenance of cell survival and function. A decrease of autophagy leads to the accumulation of damaged or even toxic components and/or energy crisis. These disturbances of intracellular homeostasis impair the processes essential for cell functions and eventually lead to a loss of these cells (Figure 3).

Importantly, the process of aging is not fully understood at present and several new concepts of aging drivers have not yet been investigated for their potential interaction with autophagy. For instance, stem cell competition for adherence to the basement membrane depending on proteolytic decrease of COL17A (Settembre et al., 2018; Liu et al., 2019) has emerged as an important process that contributes to aging of skin epithelia. Another emerging mechanism with an impact on aging is the immune surveillance of senescent cells (Ovadya et al., 2018). The potential roles of autophagy in proteolysis and antigen processing during the above-mentioned process will be interesting topics of future investigations.

\section{AUTOPHAGY IN THE DIFFERENT CELL TYPES OF THE SKIN}

The literature on roles of autophagy in the skin is largely organized into reports that focus on cell types of specific developmental origins. Here, we review these reports in separate sections, divided in epithelial and non-epithelial cell types. Nonepithelial skin cells are largely long-lived and differentiated, i.e., category 3 cells as defined in the previous sections of this article, with regard to autophagy and skin aging. Among the non-epithelial skin cells, there are also stem cells (category 1), but the changes in long-lived differentiated cells are considered the main contributors to aging. Epithelial cells of the skin include only a quantitatively minor portion of long-lived differentiated cells (category 3), such as Merkel cells and secretory cells of the sweat glands, whereas the main portion of epithelial cells are short-lived, differentiating cells (category 2), such as keratinocytes of the interfollicular epidermis, hair follicle keratinocytes, sebocytes, and sweat duct cells. The replenishment of the differentiating epithelial cells strongly depends on epithelial stem cells (category 1) (Figure 2). The contributions of autophagy to the maintenance and functions of stem cells and differentiated cells are discussed in detail below.

\section{AUTOPHAGY IN EPITHELIAL CELLS OF THE SKIN}

\section{Autophagy in Epidermal Keratinocytes}

Keratinocytes are the main cell type of the epidermis where they represent more than $95 \%$ of the total cell population and autonomously establish a stratified epithelium. Keratinocyte stem cells reside in the basal layer of the epidermis and in special locations of epidermal appendages, such as the bulge of hair follicles and the duct of sweat glands (Figure 1). Proliferating keratinocytes, so-called transit amplifying cells, require attachment to the basement membrane and therefore are also restricted to the basal layer. Upon detachment from the basement membrane, keratinocytes activate a genetically controlled terminal differentiation program that leads to the enhancement of the cytoskeleton as the cells move toward the epidermal surface and ultimately to cornification (Eckhart et al., 2013; Figures 1, 3).

Due to the fast turnover of keratinocytes, keratinocyte aging manifests mainly in changes of stem cell numbers and functions. In addition, changes in epidermal structure and stress responsiveness decrease the function of the epidermis as protection against pro-aging stress factors (Velarde, 2017). There are multiple extrinsic drivers of aging including UV irradatiation, exposure to environmental toxins, and disruptions of the barrier by low humidity, detergents, and microbes. Intrinsic drivers of aging are stem cell competition, oxidative stress due to mitochondrial dysfunctions, and others (Gilchrest and Krutmann, 2006). Keratinocyte autophagy is suppressed in carriers of a mutation in $A P 1 S 3$, leading to accumulation of p62/sequestosome-1 (Sqstm1) and inflammation (Mahil et al., 2016).

Autophagy is active both in proliferating and differentiating keratinocytes of human and mouse epidermis (Haruna et al., 2008; Rossiter et al., 2013; Sukseree et al., 2013b; Yoshihara et al., 2015). The programmed degradation of the nucleus and mitochondria during cornification is reminiscent of autophagy and, indeed, there is correlative evidence for a role of the autophagy machinery in organelle degradation within the granular layer of the epidermis (Akinduro et al., 2016). Keratinocyte-specific deletion of Atg5 and Atg7 in mice led to thickening of the stratum corneum but did not block the removal of the nucleus in cornifying keratinocytes (Rossiter et al., 2013; Sukseree et al., 2013b).

\section{Roles of Autophagy in Keratinocyte Stem Cells}

Autophagy supports the maintenance of stem cells (Cho et al., 2019). Both self-renewal and quiescence of stem cells were reported to require autophagy (García-Prat et al., 2016; Wang et al., 2018). In keratinocyte stem cells, the expression of autophagy-regulatory genes changes during the circadian rhythm and during aging (Solanas et al., 2017). Suppression of autophagy by epithelium-specific deletion of $\operatorname{Atg} 5$ or $A \operatorname{tg} 7$ can maintain a functional skin barrier during aging, suggesting that autophagy is not critically required for epidermal stem cell maintenance 
under non-stressed housing conditions of mice (Rossiter et al., 2013; Sukseree et al., 2013b). Interestingly, mice with epitheliumspecific $\operatorname{Atg} 7$ knockout developed a thicker epidermis and larger sebaceous glands than wild-type mice and thereby resembled other mouse lines with keratinocyte hyperproliferation (Rossiter et al., 2013, Rossiter et al., 2018). Quantitative studies of stem cell numbers and functions at different age of mice are needed to explore the role of autophagy in epidermal stem cells.

\section{Roles of Autophagy in Stress Resistance of Epidermal Keratinocytes}

Autophagy has been implicated in the response of keratinocytes to various types of stress, most of which accelerate skin aging. The best characterized environmental stress on skin is UV radiation which induces oxidation of skin molecules and damages the genetic material. UVB irradiation of the skin induces DNA damage and inflammation (Gilchrest, 2013). Autophagy improves DNA damage recognition by nucleotide excision repair (Qiang et al., 2016) and reduces inflammation and consequently also inflammation-enhanced tumorigenesis of the epithelium (Qiang et al., 2017). However, it has also been reported that autophagy facilitates tumor development under genotoxic stress via suppressing $\mathrm{p} 62$-mediated $\mathrm{p} 38$ activation and promotion of cell survival (Qiang et al., 2013).

UVA causes oxidation of phospholipids in keratinocytes, but it also induces autophagy which promotes the removal of these oxidation products in epidermal keratinocytes (Zhao et al., 2013). Suppression of Atg7-dependent autophagy increased DNA damage in response to UVA (Song et al., 2017). UVA irradiation also activates transcription factor EB (TFEB) and upregulates expression of p62 as well as cyclooxygenase2 (COX-2), a prostaglandin synthase implicated in skin cancer development (Sample et al., 2017). In vitro studies suggest that the levels of oxidative damage and autophagic activity determine whether senescent keratinocytes undergo programmed cell death or evade senescence with potential neoplastic activity (Deruy et al., 2014). These findings emphasize that cellular senescence, i.e., a state of arrested proliferation and altered metabolism (Muñoz-Espín and Serrano, 2014), is not only a driver of aging but also a cancer-preventive mechanism and therefore should not be regarded as entirely detrimental. In summary, the roles of autophagy in the stress responses of keratinocytes are complex and pharmaceutical modulation of autophagic activity in the epidermis should be evaluated in both homeostatic and stress conditions (Tschachler and Eckhart, 2017).

\section{Autophagy in Nail Keratinocytes}

Keratinocytes of the nail unit differentiate and cornify to become components of the nail. Genetic suppression of autophagy does not abolish growth of nails during aging (Sukseree et al., 2013b; Jaeger et al., 2019), suggesting that autophagy is dispensable for the maintenance of nail epithelial stem cells. However, the conversion of nail keratinocytes into regular cornified nail requires autophagy. Murine nails have been successfully used as a model to decipher the role of autophagy in cornification (Jaeger et al., 2019). Proteomic comparison of nails formed by autophagy-competent and by autophagy-deficient keratinocytes showed numerous differences that suggest an active participation of autophagy in cornification and a broad substrate specificity of cornificationassociated autophagy. Deletion of Atg7 in keratinocytes of the nail unit and other epidermal compartments led to a decrease in the content of keratins and keratin-associated proteins and to a concomitant increase of non-cytoskeletal proteins, including enzymes and proteins with regulatory functions. Most prominently, components of multi-protein molecular machines, such as ribosomes, chaperonins and proteasomes, accumulated upon suppression of autophagy (Jaeger et al., 2019). It appears very likely, but remains to be experimentally confirmed that autophagy plays equivalent roles in the cornification of keratinocytes in hair follicles and interfollicular epidermis (Figure 3).

\section{Autophagy in Hair Follicle Keratinocytes}

Hair is formed by a special type of cornification of keratinocytes in which essentially the entire cell is filled with crosslinked keratin filaments, and hair keratinocytes are stably interconnected to form a long fiber. The growth of hair requires a cylindrical architecture of follicles ensheathing the hair fiber. Growth of hair depends on proliferation and differentiation of keratinocytes which occur at the bottom of the follicle. At this site melanocytes deliver pigment into hair and dermal fibroblasts play important regulatory roles (Figure 1). The growth of hair is terminated when the hair fiber reaches a certain, hair type-dependent length, the fiber is shed and a new cycle of hair growth is initiated. A recent report showed that autophagy is active during hair growth in an organ culture of human scalp hair follicles and inhibition of autophagy promotes hair follicle regression (Parodi et al., 2018).

A decline in hair growth and progressive loss of active terminal hair follicles are characteristic for aging. Recently, it was shown that hair follicle stem cell aging causes the stepwise miniaturization of hair follicles and eventual hair loss in a process that that depended on the proteolysis of type XVII collagen (Matsumura et al., 2016). The cyclic growth and shedding of hair requires a complex communication between epithelial and mesenchymal cells. While autophagy is active in hair keratinocytes (Parodi et al., 2018) and mesenchymal cells surrounding hair follicles (Nicu et al., 2019), it remains to be determined whether and how autophagy contributes to the signaling between different cells of hair follicles.

Recently, small molecule activators of autophagy, such as alpha-ketoglutarate and alpha-ketobutyrate, were reported to induce a switch from telogen (the quiescent phase of the hair cycle) to anagen (the phase of active hair growth) in mice (Chai et al., 2019). Similarly, rapamycin and metformin stimulated growth of hair and their effects could be blocked by autophinib, an inhibitor of autophagosome formation (Chai et al., 2019). Studies in mouse models of alopecia and in humans are needed to determine whether the pharmacological activation of autophagy is able to counteract hair loss. 


\section{Autophagy in Sebaceous Glands}

Hair follicles are invariably associated with sebaceous glands that release sebum into the upper hair canal. The sebaceous gland is composed of acini with proliferating cells attached to the basement membrane and differentiating and lipid-accumulating cells being passively moved to the interior where they disintegrate to release a mix of lipid and other cell content into the sebaceous duct (Figure 1). This process of holocrine secretion involves degradation of the nucleus and cytoplasmic changes that are poorly characterized except for the massive accumulation of large lipid droplets (Figure 3). Suppression of autophagy by either deletion of $\operatorname{Atg} 7$ or $A \operatorname{tg} 5$ leads to premature breakdown of the nucleus in differentiating sebocytes (Sukseree et al., 2013b; Fischer et al., 2017). The current hypothesis is that autophagy contributes to the stabilization of lysosomes or to the removal of defective lysosomes in normally differentiating sebocytes, whereas lack of these maintenance and repair mechanisms allows defective lysosomes to trigger cell death that involves degradation of nuclear DNA by the lysosomal endonuclease DNase2 (Fischer et al., 2017).

\section{Autophagy in Sweat Glands}

Sweat has an essential function in thermoregulation of human skin. It is produced by secretory cells and reaches the skin surface via the duct of sweat glands. These glands are developmentally derived from K14-positive epithelial cells but most cells of the mature sweat gland reduce expression of K14 and upregulate other keratins such as K18 in the secretory portion of the glands. The cells of the secretory portion of the sweat gland do not proliferate whereas cells of the duct proliferate to maintain a connection to the surface of the constantly renewing epidermis (Lu and Fuchs, 2014). Aging of human sweat glands is characterized by the accumulation of lipofuscin, an autofluorescent mixture of oxidized proteins and lipids, in secretory sweat gland cells (Cawley et al., 1973; Sukseree et al., 2018a; Figure 1).

Deletion of Atg7 in skin epithelial cells of the mouse, in which sweat glands are restricted to toe and foot pads, led to accumulation of p62 in secretory cells of sweat glands but not in eccrine duct epithelial cells (Sukseree et al., 2018a). The size and numbers of p62 aggregates increased with age. Moreover, Atg7deficient glands showed a decrease in cellularity and an aberrant widening of the lumen. The density of functional sweat glands was significantly decreased at around 1 year of age (Sukseree et al., 2018a). Thus, autophagy is essential to suppress the accumulation of p62 during normal aging of long-lived sweat-secreting cells and to maintain the function of sweat glands (Sukseree et al., 2018a). These data should be followed up by studies of autophagic activity and its possible negative correlation with the abundance of lipofuscin deposits in human sweat glands.

\section{Autophagy in Merkel Cells}

Merkel cells are sensors of soft touch in the epidermis and hair follicles. They differentiate from epithelial cells that express keratin K5/K14 and switch to a K8/K18-dependent cytoskeleton. Merkel cells reside in the basal layer where they are either organized in touch domes or in circular arrangement in the upper part of the hair fiber (Sukseree et al., 2018b). Upon physical stimulation, they release serotonergic vesicles at synapses with nerve fibers that transmit the signal further (Figure 1). It was hypothesized that autophagy is active in Merkel cells to degrade a fraction of serotonergic vesicles and thereby to control the strength of signaling at serotonergic synapses (Sukseree et al., 2018b). The sensation of soft touch is important for spatial awareness and communication. Aging and some diseases are associated with the pathologic sensation of innocuous mechanical stimuli as itch, a phenomenon known as alloknesis (Feng et al., 2018).

In $A \operatorname{tg} 7^{f / f}$ K14-Cre mice (Sukseree et al., 2012), the deletion of Atg7 led to marked accumulation of p62 in Merkel cells, suggesting a particular requirement for autophagy in these cells (Sukseree et al., 2018b). Merkel cells have a longer life time than keratinocytes, which allows stronger accumulation of p62. Based on the studies in mouse models (Feng et al., 2018; Sukseree et al., 2018b), the potential link between the role of autophagy in Merkel cell homeostasis and aging-associated defects of touch sensation represents a promising topic of future research.

\section{Autophagy in Non-epithelial Cells of the Skin}

Besides the quantiatively predominant epithelial cells, a developmentally and functionally diverse set of other cells including melanocytes, fibroblasts, Langerhans cells, Schwann cells, and neurons reside in the skin. These cells have in common low turnover and long lifetime which predisposes them to the negative effects of declining autophagy during aging (Figure 2). Melanocytes are the most studied nonepithelial skin cells with regard to roles of autophagy. Autophagy in fibroblasts, nerves, endothelial cells, and immune cells has been studied mainly in other organs than the skin as well as in vitro.

\section{Autophagy in Melanocytes}

Melanocytes of the skin produce melanin and deliver it to neighboring keratinocytes that reside either in hair follicles, thus determining hair color, or in the interfollicular epidermis to determine complexion. Aging is associated with the changes of hair color, pallor and appearance of age spots (lentigo senilis), indicating that the function of melanocytes changes with age (Yaar and Gilchrest, 2001). The most important effect of melanocyte dysfunction in aging is graying of the hair. The follicular melanocytes which supply pigment to the hair respond to signals of the hair growth cycle, and their age-related depletion and change in shape (Itou, 2018) together with an increase in redox stress are implicated in age-related dysfunction of the hair follicle pigmentary unit (Tobin, 2015).

The incidence of melanocyte-derived cancers is generally correlated with increasing age, however, malignant melanoma is also relatively frequent in young adults. Nevus cell nevi, commonly known as moles, show age-related variations in shape and appearance (Zalaudek et al., 2006; 
Schäfer et al., 2006). Non-proliferating melanocytes in nevi show signs of cellular senescence (Tran and Rizos, 2013), nevertheless one third of melanomas derive from nevi. Current models hypothesize that mTOR signaling, which is linked to the control of autophagy, plays a role in the mechanism by which the senescent growth arrest is overcome (Damsky and Bosenberg, 2017). As the following recent studies of melanocytes indicate, autophagy may affect agerelated changes in melanogenesis, melanosome transfer, melanocyte cell death, melanocyte redox stress control, melanocyte proliferation rate, melanocyte senescence and inflammatory signaling.

\section{Roles of Autophagy in Melanogenesis, Melanosome Transfer, and Pigmentation}

Proteins of the autophagic machinery facilitate the movement of developing melanosomes within the melanocytes on microtubules and actin filaments (Ramkumar et al., 2017). The melanosomes are transferred to keratinocytes in which autophagy limits the accumulation of transferred melanin (Murase et al., 2013, 2016). Interestingly, mutations in the autophagy gene EPG5 cause a recessive neurodevelopmental multisystem disorder, Vici syndrome, which is associated with hypopigmentation (Cullup et al., 2013).

Our group has observed mild but age-correlated effects on pigmentation in mice devoid of Atg7-dependent autophagy in melanocytes. The deletion of Atg7 under the control of the Tyrosinase promoter resulted in age-dependent changes of skin pigmentation (Zhang et al., 2015), accumulation of p62 in pigment cells of the eye (Sukseree et al., 2016), and aging-related p62 aggregation in neurons and neuroepithelial cells (Sukseree et al., 2018c). Atg7-deficient skin melanocytes developed premature senescence and showed a dysregulated antioxidant response and lipid homeostasis in culture (Zhang et al., 2015). We observed hyperinduction of the redox responsive Nrf2 system, probably due to accumulation of the autophagy adaptor and Nrf2 agonist p62, which did not prevent elevated melanocyte redox stress. The autophagy deficient melanocytes displayed a senescence associated secretory phenotype (SASP) (Ni et al., 2016). This low-grade inflammation is typical for senescent cells, and melanocyte SASP is implicated in the pathogenesis of vitiligo (Bellei et al., 2013; Qiao et al., 2016) and hypopigmented macules in tuberous sclerosis complex (Yang et al., 2018).

\section{Roles of Autophagy in Melanocyte Senescence, Proliferation, and Death}

Several recent studies have established links between autophagy and the control of proliferation, senescence and death of melanocytes as well as melanoma cells. The autophagy gene ATG5 is expressed at reduced levels in melanoma but not in benign melanocytes in nevi (Liu et al., 2013). In melanoma cells cultured in vitro, activation of ATG5 reduced proliferation and induced senescence. The authors concluded that in early stages of melanoma development, inhibition of autophagy might delay the onset of oncogene-induced senescence and promote uncontrolled proliferation of melanocytes (Liu et al., 2013). Sample and colleagues reported that the autophagy adapter p62, which we had found to accumulate in melanocytes upon UVA exposure (Zhang et al., 2015), was elevated in abundance in both nevi and malignant melanoma, and proposed p62 as an oncogene in melanoma development (Sample et al., 2018). In a different study, pharmacological blockade of autophagy sensitized melanoma cells to chemotherapy induced cell death (Qiao et al., 2013). In contrast, starvation elevated both autophagy and cisplatin chemotoxicity in a murine model (Antunes et al., 2018). One of the possible connectors of autophagy, cell cycle control and aging in melanocytes and melanoma is the p53 activating protein ARF, which acts as emergency control of superoxide levels in mitochondrial dysfunction. This protein is rendered non-functional in suppressing superoxide and melanoma cell proliferation when $C D K N 2 A$ is mutated (Christensen et al., 2014). ARF is however also an autophagy agonist (Balaburski et al., 2010), and this activity does not depend on the CDKN2A mutation. Whether modulation of autophagy would be an advisable strategy to promote the success of chemotherapy, or biologics will need further in-depth investigation (Li et al., 2019).

\section{Autophagy in Dermal Fibroblasts}

The fibroblasts of the human dermis are long-lived cells and thus prone to accumulate intrinsic and extrinsic damage. Dermal fibroblasts do not represent a uniform population because they can take on at least two phenotypes, i.e., papillary and reticular (Driskell et al., 2013). The phenotypic plasticity of fibroblasts likely depends on the microenvironment (Korosec et al., 2019), in which the ECM is undergoes aging-related changes (Larroque-Cardoso et al., 2015). During skin aging the balance between these two fibroblast types shifts toward the reticular lineage phenotype (Mine et al., 2008).

Changes in autophagic flux in fibroblasts have been implicated in aging (Dumit et al., 2014; Demirovic et al., 2015; Kim et al., 2018). Recent findings discussed below suggest that autophagy and its age-related dysfunction may affect the microenvironment in chronologic and UV-induced aging as well as in premature aging phenotypes.

\section{Roles of Fibroblast Autophagy in Premature Aging and Age-Related Diseases}

Cockayne syndrome is a premature aging disease affecting the skin and causing UV hypersensitivity and subcutaneous fat wasting. Fibroblasts from patients deficient in Cockayne syndrome $\mathrm{B}$ (CSB) protein display impaired autophagy due to interaction of CSB with HDAC6 and cytoskeletal components. Importantly, the restoration of autophagic function could revert the premature aging and photosensitivity phenotype in a CSB mouse model (Majora et al., 2018). The movement of the autophagic-lysosomal components along cytoskeletal components through motor proteins was demonstrated in a study in mouse fibroblasts. A genetic reduction of the motor 
protein KIF3C led to diminished autophagic flux and impaired proteostasis, similar in effect to a reduction of KIFC3 levels in naturally aged cells (Bejarano et al., 2018). Autophagy degraded nuclear anomalies resulting from mutation of lamin A (Park et al., 2009), and stimulation of autophagy and the connected Nrf2-mediated antioxidant response promote the clearance of the truncated pre-lamin A protein (progerin) which accumulates in fibroblasts of patients with Hutchinson Gilford progeria (Gabriel et al., 2017). Dermal fibroblasts from Parkinson's disease patients displayed dysfunctional autophagy, mitochondrial damage, and impaired redox stress tolerance (Teves et al., 2018). The skin is a potential source of prognostic biomarkers for age-related neurodegenerative diseases (Can Akerman et al., 2019), and markers related to skin fibroblasts may also be relevant for disease-free skin aging.

\section{Roles of Autophagy in Proteostasis of Aging Fibroblasts}

Loss of homeostasis in protein quality control - termed proteostasis - and thereby the accumulation of oxidized proteins is observed in the chronologic and photo-aging processes of the skin (Tigges et al., 2014). Proteostasis was identified as the ontology category predominantly affected by aging of human fibroblasts (Waldera-Lupa et al., 2014). Loss of proteostasis is attributed to dysregulation of the proteasome and autophagy in aging (Korovila et al., 2017). A comparison of proteostasis in phylogenetically related shortand long-lived mammalian species indicated higher autophagic activity in the longer lived species (Pride et al., 2015). In humans, loss of proteostasis has been observed in skin fibroblasts upon chronologic aging and UV exposure (Bulteau et al., 2007). The loss of capacity to remove oxidized and misfolded protein can lead to activation of DNA damage repair (DDR) pathways and thereby to the induction of cellular senescence (Chondrogianni and Gonos, 2008) and SASP (Catalgol and Grune, 2009).

Fibroblast autophagy is required for clearance of lipofuscin, an accumulation of misfolded and modified proteins and lipids (Höhn et al., 2012). Impairment of autophagy in senescent human fibroblasts (Ott et al., 2016) may thus be related to the aberrant deposition of lipofuscin that underlies age-related pigmentation irregularities. Declining autophagy in aging dermal fibroblasts was also implicated in another hallmark of skin aging, i.e., modifications of the ECM (Tashiro et al., 2014).

\section{Roles of Autophagy in the Control of DNA Damage in Fibroblasts}

The function of autophagy in the protection against stress and damage was investigated in several studies on effects of ultraviolet irradiation of fibroblasts. UVB exposure, which promotes photoaging and senescence of dermal fibroblasts, induced proteasome inhibition and autophagy (Cavinato and Jansen-Dürr, 2017), whereas chronic UVA exposure led to blockage of autophagic flux (Lamore and Wondrak, 2013). In vitro, activation of autophagy by rapamycin prevented
UVB induced senescence by limiting ROS production (Qin et al., 2018). Autophagy was proposed to be required for UV mediated senescence induction (Cavinato and JansenDürr, 2017; Sample and He, 2017) but this hypothesis remains to be tested in different cells under different regimens of UV exposure. Current evidence suggests that autophagy counteracts the accumulation of damage that promotes cellular senescence.

\section{CONCLUSION}

Skin aging is a complex process which, according to the concept described above, depends on changes in three categories of cells with differential roles of autophagy. Epithelial stem cells require autophagy for homeostasis during their long lifetime whereas short-lived differentiating epithelial cells utilize autophagy mainly for intracellular remodeling. Long-lived differentiated cells of both epithelial and non-epithelial origin need autophagy to suppress the accumulation of noxious compounds. We propose that inefficiencies of cellular processes (intrinsic drivers of aging) and damaging effects from the environment (extrinsic drivers of aging) compromise the machinery of autophagy, leading to a self-accelerating decline in cellular waste disposal and recycling in long-lived skin cells and decreasing protective functions of skin epithelia. Together, autophagy-dependent and independent processes lead to tissues changes that manifest in skin aging. Further characterization of autophagy in distinct skin cells may help to identify new approaches for maintaining the normal function of the skin in aged individuals.

\section{AUTHOR CONTRIBUTIONS}

LE, ET, and FG wrote the manuscript.

\section{FUNDING}

This work was supported by funding from the Federal Ministry for Digital and Economic Affairs of Austria and the National Foundation for Research, Technology and Development of Austria to the Christian Doppler Laboratory for Biotechnology of Skin Aging, grants from the Herzfelder'sche Familienstiftung to FG and LE, and a research grant from Chanel R\&T, Pantin, France to the Department of Dermatology, Medical University of Vienna.

\section{ACKNOWLEDGMENTS}

The authors thank Supawadee Sukseree and Marie Sophie Narzt for helpful discussions. LE and FG participated in the COST Action CA15138, European Network of Multidisciplinary Research and Translation of Autophagy knowledge (TRANSAUTOPHAGY) that is supported by the European Union Framework Programme Horizon 2020. 


\section{REFERENCES}

Akinduro, O., Sully, K., Patel, A., Robinson, D. J., Chikh, A., McPhail, G., et al. (2016). Constitutive autophagy and nucleophagy during epidermal differentiation. J. Invest. Dermatol. 136, 1460-1470. doi: 10.1016/j.jid.2016. 03.016

Antunes, F., Pereira, G. J., Jasiulionis, M. G., Bincoletto, C., and Smaili, S. S. (2018). Nutritional shortage augments cisplatin-effects on murine melanoma cells. Chem. Biol. Interact. 281, 89-97. doi: 10.1016/j.cbi.2017.12.027

Balaburski, G. M., Hontz, R. D., and Murphy, M. E. (2010). p53 and ARF: unexpected players in autophagy. Trends Cell Biol. 20, 363-369. doi: 10.1016/ j.tcb.2010.02.007

Bejarano, E., Murray, J. W., Wang, X., Pampliega, O., Yin, D., Patel, B., et al. (2018). Defective recruitment of motor proteins to autophagic compartments contributes to autophagic failure in aging. Aging Cell 17:e12777. doi: 10.1111/ acel. 12777

Bellei, B., Pitisci, A., Ottaviani, M., Ludovici, M., Cota, C., Luzi, F., et al. (2013). Vitiligo: a possible model of degenerative diseases. PLoS One 8:e59782. doi: 10.1371/journal.pone.0059782

Botchkarev, V. A. (2017). Second international symposium-Epigenetic regulation of skin regeneration and aging: from chromatin biology towards the understanding of epigenetic basis of skin diseases. J. Invest. Dermatol. 137, 1604-1608. doi: 10.1016/j.jid.2017.01.037

Boya, P., Codogno, P., and Rodriguez-Muela, N. (2018). Autophagy in stem cells: repair, remodelling and metabolic reprogramming. Development 145:dev146506. doi: 10.1242/dev.146506

Boya, P., Reggiori, F., and Codogno, P. (2013). Emerging regulation and functions of autophagy. Nat. Cell Biol. 15, 713-720. doi: 10.1038/ncb2788

Bruckner-Tuderman, L. (2012). "Biology of the extracellular matrix," in Dermatology, eds J. L. Bolognia, J. L. Jorizzl, and J. V. Schaffer (St. Louis, MO: Elsevier), 1585-1598.

Bulteau, A. L., Moreau, M., Nizard, C., and Friguet, B. (2007). Proteasome and photoaging: the effects of UV irradiation. Ann. N. Y. Acad. Sci. 1100, 280-290. doi: 10.1196/annals.1395.029

Can Akerman, S., Hossain, S., Shobo, A., Zhong, Y., Jourdain, R., Hancock, M., et al. (2019). Neurodegenerative disease-related proteins within the epidermal layer of the human skin. J. Alzheimers Dis. 69, 463-478. doi: 10.3233/JAD181191

Catalgol, B., and Grune, T. (2009). Protein pool maintenance during oxidative stress. Curr. Pharm. Des. 15, 3043-3051. doi: 10.2174/138161209789058129

Cavinato, M., and Jansen-Dürr, P. (2017). Molecular mechanisms of UVB-induced senescence of dermal fibroblasts and its relevance for photoaging of the human skin. Exp. Gerontol. 94, 78-82. doi: 10.1016/j.exger.2017.01.009

Cawley, E. P., Hsu, Y. T., Sturgill, B. C., and Harman, L. E. Jr. (1973). Lipofuscin ("wear and tear pigment") in human sweat glands. J. Invest. Dermatol. 61, 105-107. doi: 10.1111/1523-1747.ep12675428

Chai, M., Jiang, M., Vergnes, L., Fu, X., de Barros, S. C., Doan, N. B., et al. (2019). Stimulation of hair growth by small molecules that activate autophagy. Cell Rep. 27, 3413-3421. doi: 10.1016/j.celrep.2019.05.070

Chang, A. L. S. (2016). Expanding our understanding of human skin aging. J. Invest. Dermatol. 136, 897-899. doi: 10.1016/j.jid.2016.02.020

Cho, I. J., Lui, P. P., Obajdin, J., Riccio, F., Stroukov, W., Willis, T. L., et al. (2019). Mechanisms, hallmarks, and implications of stem cell quiescence. Stem Cell Rep. 12, 1190-1200. doi: 10.1016/j.stemcr.2019.05.012

Chondrogianni, N., and Gonos, E. S. (2008). Proteasome activation as a novel antiaging strategy. IUBMB Life 60, 651-655. doi: 10.1002/iub.99

Christensen, C., Bartkova, J., Mistrík, M., Hall, A., Lange, M. K., Ralfkiær, U., et al. (2014). A short acidic motif in ARF guards against mitochondrial dysfunction and melanoma susceptibility. Nat. Commun. 5:5348. doi: 10.1038/ncomms6348

Cullup, T., Kho, A. L., Dionisi-Vici, C., Brandmeier, B., Smith, F., Urry, Z., et al. (2013). Recessive mutations in EPG5 cause Vici syndrome, a multisystem disorder with defective autophagy. Nat. Genet. 45, 83-87. doi: 10.1038/ng.2497

Damsky, W. E., and Bosenberg, M. (2017). Melanocytic nevi and melanoma: unraveling a complex relationship. Oncogene $36,5771-5792$. doi: 10.1038 /onc. 2017.189

Das, L. M., Binko, A. M., Traylor, Z. P., Peng, H., and Lu, K. Q. (2019). Vitamin $\mathrm{D}$ improves sunburns by increasing autophagy in M2 macrophages. Autophagy 15, 813-826. doi: 10.1080/15548627.2019.1569298
Demirovic, D., Nizard, C., and Rattan, S. I. (2015). Basal level of autophagy is increased in aging human skin fibroblasts in vitro, but not in old skin. PLoS One 10:e0126546. doi: 10.1371/journal.pone.0126546

Deruy, E., Nassour, J., Martin, N., Vercamer, C., Malaquin, N., Bertout, J., et al. (2014). Level of macroautophagy drives senescent keratinocytes into cell death or neoplastic evasion. Cell Death Dis. 5:e1577. doi: 10.1038/cddis.2014.533

Driskell, R. R., Lichtenberger, B. M., Hoste, E., Kretzschmar, K., Simons, B. D., Charalambous, M., et al. (2013). Distinct fibroblast lineages determine dermal architecture in skin development and repair. Nature 504, 277-281. doi: 10.1038/ nature 12783

Dufour, A., and Candas, V. (2007). Aging and thermal responses during passive heat exposure: sweating and sensory aspects. Eur. J. Appl. Physiol. 100, 19-26. doi: 10.1007/s00421-007-0396-9

Dumit, V. I., Küttner, V., Käppler, J., Piera-Velazquez, S., Jimenez, S. A., BrucknerTuderman, L., et al. (2014). Altered MCM protein levels and autophagic flux in aged and systemic sclerosis dermal fibroblasts. J. Invest. Dermatol. 134, 2321-2330. doi: 10.1038/jid.2014.69

Eckhart, L., Lippens, S., Tschachler, E., and Declercq, W. (2013). Cell death by cornification. Biochim. Biophys. Acta 1833, 3471-3480. doi: 10.1016/j.bbamcr. 2013.06.010

Eckhart, L., and Zeeuwen, P. L. J. M. (2018). The skin barrier: epidermis versus environment. Exp. Dermatol. 27, 805-806. doi: 10.1111/exd.13731

Feng, J., Luo, J., Yang, P., Du, J., Kim, B. S., and Hu, H. (2018). Piezo2 channelMerkel cell signaling modulates the conversion of touch to itch. Science 360, 530-533. doi: 10.1126/science.aar5703

Fernandez-Flores, A., Saeb-Lima, M., and Cassarino, D. S. (2019). Histopathology of aging of the hair follicle. J. Cutan. Pathol. doi: 10.1111/cup.13467. [Epub ahead of print].

Fischer, H., Fumicz, J., Rossiter, H., Napirei, M., Buchberger, M., Tschachler, E., et al. (2017). Holocrine secretion of sebum is a unique DNase2-dependent mode of programmed cell death. J. Invest. Dermatol. 137, 587-594. doi: 10.1016/j.jid. 2016.10.017

Fisher, G. J., Wang, Z. Q., Datta, S. C., Varani, J., Kang, S., and Voorhees, J. J. (1997). Pathophysiology of premature skin aging induced by ultraviolet light. N. Engl. J. Med. 337, 1419-1428.

Gabriel, D., Shafry, D. D., Gordon, L. B., and Djabali, K. (2017). Intermittent treatment with farnesyltransferase inhibitor and sulforaphane improves cellular homeostasis in Hutchinson-Gilford progeria fibroblasts. Oncotarget 8, 6480964826. doi: 10.18632/oncotarget.19363

García-Prat, L., Martínez-Vicente, M., Perdiguero, E., Ortet, L., RodríguezUbreva, J., Rebollo, E., et al. (2016). Autophagy maintains stemness by preventing senescence. Nature 529, 37-42. doi: 10.1038/nature16187

Galluzzi, L., Baehrecke, E. H., Ballabio, A., Boya, P., Bravo-San Pedro, J. M., Cecconi, F., et al. (2017). Molecular definitions of autophagy and related processes. EMBO J. 36, 1811-1836. doi: 10.15252/embj.201796697

Ghosh, K., and Capell, B. C. (2016). The senescence-associated secretory phenotype: critical effector in skin cancer and aging. J. Invest. Dermatol. 136, 2133-2139. doi: 10.1016/j.jid.2016.06.621

Gilchrest, B. A. (2013). Photoaging. J. Invest. Dermatol. 133, E2-E6. doi: 10.1038/ skinbio. 2013.176

Gilchrest, B. A., and Krutmann, J. (2006). Skin Aging. Berlin: Springer-Verlag.

Guinot, C., Malvy, D. J., Ambroisine, L., Latreille, J., Mauger, E., Tenenhaus, M., et al. (2002). Relative contribution of intrinsic vs extrinsic factors to skin aging as determined by a validated skin age score. Arch. Dermatol. 138, 1454-1460.

Hansen, M., Rubinsztein, D. C., and Walker, D. W. (2018). Autophagy as a promoter of longevity: insights from model organisms. Nat. Rev. Mol. Cell Biol. 19, 579-593. doi: 10.1038/s41580-018-0033-y

Haruna, K., Suga, Y., Muramatsu, S., Taneda, K., Mizuno, Y., Ikeda, S., et al. (2008). Differentiation-specific expression and localization of an autophagosomal marker protein $\left(\mathrm{LC}_{3}\right)$ in human epidermal keratinocytes. J. Dermatol. Sci. 52, 213-215. doi: 10.1016/j.jdermsci.2008.07.005

Höhn, A., Sittig, A., Jung, T., Grimm, S., and Grune, T. (2012). Lipofuscin is formed independently of macroautophagy and lysosomal activity in stressinduced prematurely senescent human fibroblasts. Free Radic. Biol. Med. 53, 1760-1769. doi: 10.1016/j.freeradbiomed.2012.08.591

Itou, T. (2018). Morphological changes in hair melanosomes by aging. Pigment Cell Melanoma Res. 31, 630-635. doi: 10.1111/pcmr. 12697 
Jaeger, K., Sukseree, S., Zhong, S., Phinney, B. S., Mlitz, V., Buchberger, M., et al. (2019). Cornification of nail keratinocytes requires autophagy for bulk degradation of intracellular proteins while sparing components of the cytoskeleton. Apoptosis 24, 62-73. doi: 10.1007/s10495-0181505-4

Jonason, A. S., Kunala, S., Price, G. J., Restifo, R. J., Spinelli, H. M., Persing, J. A., et al. (1996). Frequent clones of p53-mutated keratinocytes in normal human skin. Proc. Natl. Acad. Sci. U.S.A. 93, 14025-14029. doi: 10.1073/pnas.93.24. 14025

Kim, H. S., Park, S. Y., Moon, S. H., Lee, J. D., and Kim, S. (2018). Autophagy in human skin fibroblasts: impact of age. Int. J. Mol. Sci. 19:E2254. doi: 10.3390/ ijms 19082254

Kligman, A. M., and Balin, A. K. (1989). “Aging of human skin,” in Aging and the Skin, eds A. K. Balin and A. M. Kligman (New York, NY: Raven Press).

Korosec, A., Frech, S., Gesslbauer, B., Vierhapper, M., Radtke, C., Petzelbauer, P., et al. (2019). Lineage identity and location within the dermis determine the function of papillary and reticular fibroblasts in human skin. J. Invest. Dermatol. 139, 342-351. doi: 10.1016/j.jid.2018.07.033

Korovila, I., Hugo, M., Castro, J. P., Weber, D., Höhn, A., Grune, T., et al. (2017). Proteostasis, oxidative stress and aging. Redox Biol. 13, 550-567. doi: 10.1016/j. redox.2017.07.008

Lamore, S. D., and Wondrak, G. T. (2013). UVA causes dual inactivation of cathepsin B and L underlying lysosomal dysfunction in human dermal fibroblasts. J. Photochem. Photobiol. B 123, 1-12. doi: 10.1016/j.jphotobiol.2013. 03.007

Larroque-Cardoso, P., Camaré, C., Nadal-Wollbold, F., Grazide, M. H., Pucelle, M., Garoby-Salom, S., et al. (2015). Elastin modification by 4-hydroxynonenal in hairless mice exposed to UV-A. Role in photoaging and actinic elastosis. J. Invest. Dermatol. 135, 1873-1881. doi: 10.1038/jid.2015.84

Leidal, A. M., Levine, B., and Debnath, J. (2018). Autophagy and the cell biology of age-related disease. Nat. Cell Biol. 20, 1338-1348. doi: 10.1038/s41556-0180235-8

Levine, B., and Kroemer, G. (2019). Biological functions of autophagy genes: a disease perspective. Cell 176, 11-42. doi: 10.1016/j.cell.2018.09.048

Li, S., Song, Y., Quach, C., Guo, H., Jang, G. B., Maazi, H., et al. (2019). Transcriptional regulation of autophagy-lysosomal function in BRAF-driven melanoma progression and chemoresistance. Nat. Commun. 10:1693. doi: 10. 1038/s41467-019-09634-8

Liu, H., He, Z., von Rütte, T., Yousefi, S., Hunger, R. E., and Simon, H. U. (2013). Down-regulation of autophagy-related protein 5 (ATG5) contributes to the pathogenesis of early-stage cutaneous melanoma. Sci. Transl. Med. 5:202ra123. doi: $10.1126 /$ scitranslmed.3005864

Liu, N., Matsumura, H., Kato, T., Ichinose, S., Takada, A., Namiki, T., et al. (2019). Stem cell competition orchestrates skin homeostasis and ageing. Nature 568, 344-350. doi: 10.1038/s41586-019-1085-7

López-Otín, C., Blasco, M. A., Partridge, L., Serrano, M., and Kroemer, G. (2013). The hallmarks of aging. Cell 153, 1194-1217. doi: 10.1016/j.cell.2013.05.039

Lu, C., and Fuchs, E. (2014). Sweat gland progenitors in development, homeostasis, and wound repair. Cold Spring Harb. Perspect. Med. 4:a015222. doi: 10.1101/ cshperspect.a015222

Mahil, S. K., Twelves, S., Farkas, K., Setta-Kaffetzi, N., Burden, A. D., Gach, J. E., et al. (2016). AP1S3 mutations cause skin autoinflammation by disrupting keratinocyte autophagy and up-regulating IL-36 production. J. Invest. Dermatol. 136, 2251-2259. doi: 10.1016/j.jid.2016.06.618

Majora, M., Sondenheimer, K., Knechten, M., Uthe, I., Esser, C., Schiavi, A., et al. (2018). HDAC inhibition improves autophagic and lysosomal function to prevent loss of subcutaneous fat in a mouse model of Cockayne syndrome. Sci. Transl. Med. 10:eaam7510. doi: 10.1126/scitranslmed.aam7510

Matsumura, H., Mohri, Y., Binh, N. T., Morinaga, H., Fukuda, M., Ito, M., et al. (2016). Hair follicle aging is driven by transepidermal elimination of stem cells via COL17A1 proteolysis. Science 351:aad4395. doi: 10.1126/science.aad4395

McGlone, F., and Reilly, D. (2010). The cutaneous sensory system. Neurosci. Biobehav. Rev. 34, 148-159. doi: 10.1016/j.neubiorev.2009.08.004

McGrath, J. A. (2005). “The structure and function of skin," in Pathology of the Skin, eds P. H. McKee, E. Calonje, S. R. Granter, and T. Brann (St Louis, MO: Elsevier), 1-36.

Mine, S., Fortunel, N. O., Pageon, H., and Asselineau, D. (2008). Aging alters functionally human dermal papillary fibroblasts but not reticular fibroblasts: a new view of skin morphogenesis and aging. PLoS One 3:e4066. doi: 10.1371/ journal.pone.0004066

Muñoz-Espín, D., and Serrano, M. (2014). Cellular senescence: from physiology to pathology. Nat. Rev. Mol. Cell Biol. 15, 482-496. doi: 10.1038/nrm3823

Murase, D., Hachiya, A., Fullenkamp, R., Beck, A., Moriwaki, S., Hase, T., et al. (2016). Variation in Hsp70-1A expression contributes to skin color diversity. J. Invest. Dermatol. 136, 1681-1691. doi: 10.1016/j.jid.2016.03.038

Murase, D., Hachiya, A., Takano, K., Hicks, R., Visscher, M. O., Kitahara, T., et al. (2013). Autophagy has a significant role in determining skin color by regulating melanosome degradation in keratinocytes. J. Invest. Dermatol. 133, 2416-2424. doi: 10.1038/jid.2013.165

Ni, C., Narzt, M. S., Nagelreiter, I. M., Zhang, C. F., Larue, L., Rossiter, H., et al. (2016). Autophagy deficient melanocytes display a senescence associated secretory phenotype that includes oxidized lipid mediators. Int. J. Biochem. Cell Biol. 81(Pt B), 375-382. doi: 10.1016/j.biocel.2016. 10.006

Nicu, C., Hardman, J. A., Pople, J., and Paus, R. (2019). Do human dermal adipocytes switch from lipogenesis in anagen to lipophagy and lipolysis during catagen in the human hair cycle? Exp. Dermatol. 28, 432-435. doi: 10.1111/exd. 13904

Ott, C., König, J., Höhn, A., Jung, T., and Grune, T. (2016). Macroautophagy is impaired in old murine brain tissue as well as in senescent human fibroblasts. Redox Biol. 10, 266-273. doi: 10.1016/j.redox.2016.10.015

Ovadya, Y., Landsberger, T., Leins, H., Vadai, E., Gal, H., Biran, A., et al. (2018). Impaired immune surveillance accelerates accumulation of senescent cells and aging. Nat. Commun. 9:5435. doi: 10.1038/s41467-018-0 7825-3

Park, Y. E., Hayashi, Y. K., Bonne, G., Arimuram, T., Noguchim, S., Nonakam, I., et al. (2009). Autophagic degradation of nuclear components in mammalian cells. Autophagy 5, 795-804. doi: 10.4161/auto.8901

Parodi, C., Hardman, J. A., Allavena, G., Marotta, R., Catelani, T., Bertolini, M., et al. (2018). Autophagy is essential for maintaining the growth of a human (mini-)organ: evidence from scalp hair follicle organ culture. PLoS Biol. 16:e2002864. doi: 10.1371/journal.pbio.2002864

Pride, H., Yu, Z., Sunchu, B., Mochnick, J., Coles, A., Zhang, Y., et al. (2015). Long-lived species have improved proteostasis compared to phylogeneticallyrelated shorter-lived species. Biochem. Biophys. Res. Commun. 457, 669-675. doi: 10.1016/j.bbrc.2015.01.046

Qiang, L., Sample, A., Shea, C. R., Soltani, K., Macleod, K. F., and He, Y. Y. (2017). Autophagy gene ATG7 regulates ultraviolet radiation-induced inflammation and skin tumorigenesis. Autophagy 13, 2086-2103. doi: 10.1080/15548627.2017. 1380757

Qiang, L., Wu, C., Ming, M., Viollet, B., and He, Y. Y. (2013). Autophagy controls p38 activation to promote cell survival under genotoxic stress. J. Biol. Chem. 288, 1603-1611. doi: 10.1074/jbc.M112.415224

Qiang, L., Zhao, B., Shah, P., Sample, A., Yang, S., and He, Y. Y. (2016). Autophagy positively regulates DNA damage recognition by nucleotide excision repair. Autophagy 12, 357-368. doi: 10.1080/15548627.2015.1110667

Qiao, S., Tao, S., Rojo de la Vega, M., Park, S. L., Vonderfecht, A. A., Jacobs, S. L., et al. (2013). The antimalarial amodiaquine causes autophagic-lysosomal and proliferative blockade sensitizing human melanoma cells to starvation- and chemotherapy-induced cell death. Autophagy 9, 2087-2102. doi: 10.4161/auto. 26506

Qiao, Z., Wang, X., Xiang, L., and Zhang, C. (2016). Dysfunction of autophagy: a possible mechanism involved in the pathogenesis of vitiligo by breaking the redox balance of melanocytes. Oxid. Med. Cell. Longev. 2016:3401570. doi: 10.1155/2016/3401570

Qin, D., Ren, R., Jia, C., Lu, Y., Yang, Q., Chen, L., et al. (2018). Rapamycin protects skin fibroblasts from ultraviolet B-induced photoaging by suppressing the production of reactive oxygen species. Cell Physiol. Biochem. 46, 1849-1860. doi: $10.1159 / 000489369$

Ramkumar, A., Murthy, D., Raja, D. A., Singh, A., Krishnan, A., Khanna, S., et al. (2017). Classical autophagy proteins LC3B and ATG4B facilitate melanosome movement on cytoskeletal tracks. Autophagy 13, 1331-1347. doi: 10.1080/ 15548627.2017.1327509

Rinnerthaler, M., and Richter, K. (2018). The influence of calcium on the skin pH and epidermal barrier during aging. Curr. Probl. Dermatol. 54, 79-86. doi: $10.1159 / 000489521$ 
Rossiter, H., König, U., Barresi, C., Buchberger, M., Ghannadan, M., Zhang, C. F., et al. (2013). Epidermal keratinocytes form a functional skin barrier in the absence of Atg7 dependent autophagy. J. Dermatol. Sci. 71, 67-75. doi: 10.1016/ j.jdermsci.2013.04.015

Rossiter, H., Stübiger, G., Gröger, M., König, U., Gruber, F., Sukseree, S., et al. (2018). Inactivation of autophagy leads to changes in sebaceous gland morphology and function. Exp. Dermatol. 27, 1142-1151. doi: 10.1111/exd. 13752

Rubinsztein, D. C., Mariño, G., and Kroemer, G. (2011). Autophagy and aging. Cell 146, 682-695.

Sample, A., and He, Y. Y. (2017). Autophagy in UV damage response. Photochem. Photobiol. 93, 943-955. doi: 10.1111/php.12691

Sample, A., Zhao, B., Qiang, L., and He, Y. Y. (2017). Adaptor protein p62 promotes skin tumor growth and metastasis and is induced by UVA radiation. J. Biol. Chem. 292, 14786-14795. doi: 10.1074/jbc.M117.786160

Sample, A., Zhao, B., Wu, C., Qian, S., Shi, X., Aplin, A., et al. (2018). The autophagy receptor adaptor p62 is up-regulated by UVA radiation in melanocytes and in melanoma cells. Photochem. Photobiol. 94, 432-437. doi: $10.1111 /$ php. 12809

Schäfer, T., Merkl, J., Klemm, E., Wichmann, H. E., Ring, J., and Kora Study Group (2006). The epidemiology of nevi and signs of skin aging in the adult general population: results of the KORA-survey 2000. J. Invest. Dermatol. 126, 1490-1496. doi: 10.1038/sj.jid.5700269

Settembre, C., Cinque, L., Bartolomeo, R., Di Malta, C., De Leonibus, C., and Forrester, A. (2018). Defective collagen proteostasis and matrix formation in the pathogenesis of lysosomal storage disorders. Matrix Biol. 71-72, 283-293. doi: 10.1016/j.matbio.2018.06.001

Sil, P., Wong, S. W., and Martinez, J. (2018). More than skin deep: autophagy is vital for skin barrier function. Front. Immunol. 9:1376. doi: 10.3389/fimmu. 2018.01376

Solanas, G., Peixoto, F. O., Perdiguero, E., Jardí, M., Ruiz-Bonilla, V., Datta, D., et al. (2017). Aged stem cells reprogram their daily rhythmic functions to adapt to stress. Cell 170, 678-692. doi: 10.1016/j.cell.2017.07.035

Song, X., Narzt, M. S., Nagelreiter, I. M., Hohensinner, P., Terlecki-Zaniewicz, L., Tschachler, E., et al. (2017). Autophagy deficient keratinocytes display increased DNA damage, senescence and aberrant lipid composition after oxidative stress in vitro and in vivo. Redox Biol. 11, 219-230. doi: 10.1016/j.redox.2016. 12.015

Sukseree, S., Bergmann, S., Pajdzik, K., Sipos, W., Gruber, F., Tschachler, E., et al. (2018a). Suppression of epithelial autophagy compromises the homeostasis of sweat glands during aging. J. Invest. Dermatol. 138, 2061-2063. doi: 10.1016/j. jid.2018.03.1502

Sukseree, S., Bergmann, S., Pajdzik, K., Tschachler, E., and Eckhart, L. (2018b). Suppression of autophagy perturbs turnover of sequestosome-1/p62 in Merkel cells but not in keratinocytes. J. Dermatol. Sci. 90, 209-211. doi: 10.1016/j. jdermsci.2018.01.008

Sukseree, S., László, L., Gruber, F., Bergmann, S., Narzt, M. S., Nagelreiter, I. M., et al. (2018c). Filamentous aggregation of sequestosome-1/p62 in brain neurons and neuroepithelial cells upon Tyr-Cre-mediated deletion of the autophagy gene Atg7. Mol. Neurobiol. 55, 8425-8437. doi: 10.1007/s12035-0180996-x

Sukseree, S., Chen, Y. T., Laggner, M., Gruber, F., Petit, V., Nagelreiter, I. M., et al. (2016). Tyrosinase-Cre-mediated deletion of the autophagy gene Atg7 leads to accumulation of the RPE65 variant M450 in the retinal pigment epithelium of C57BL/6 mice. PLoS One 11:e0161640. doi: 10.1371/journal.pone.01 61640

Sukseree, S., Eckhart, L., Tschachler, E., and Watanapokasin, R. (2013a). Autophagy in epithelial homeostasis and defense. Front. Biosci. 5, 1000-1010. doi: 10.2741/ e679

Sukseree, S., Rossiter, H., Mildner, M., Pammer, J., Buchberger, M., Gruber, F., et al. (2013b). Targeted deletion of Atg5 reveals differential roles of autophagy in keratin K5-expressing epithelia. Biochem. Biophys. Res. Commun. 430, 689-694. doi: 10.1016/j.bbrc.2012.11.090

Sukseree, S., Mildner, M., Rossiter, H., Pammer, J., Zhang, C.-F., Watanapokasin, R., et al. (2012). Autophagy in the thymic epithelium is dispensable for the development of self-tolerance in a novel mouse model. PLoS One 7:e38933. doi: 10.1371/journal.pone.0038933

Tashiro, K., Shishido, M., Fujimoto, K., Hirota, Y., Yo, K., Gomi, T., et al. (2014). Age-related disruption of autophagy in dermal fibroblasts modulates extracellular matrix components. Biochem. Biophys. Res. Commun. 443, $167-$ 172. doi: 10.1016/j.bbrc.2013.11.066

Tekirdag, K., and Cuervo, A. M. (2018). Chaperone-mediated autophagy and endosomal microautophagy: joint by a chaperone. J. Biol. Chem. 293, 54145424. doi: 10.1074/jbc.R117.818237

Teves, J. M. Y., Bhargava, V., Kirwan, K. R., Corenblum, M. J., Justiniano, R., Wondrak, G. T., et al. (2018). Parkinson's disease skin fibroblasts display signature alterations in growth, redox homeostasis, mitochondrial function, and autophagy. Front. Neurosci. 11:737. doi: 10.3389/fnins.2017.00737

Tigges, J., Krutmann, J., Fritsche, E., Haendeler, J., Schaal, H., Fischer, J. W., et al. (2014). The hallmarks of fibroblast ageing. Mech. Ageing Dev. 138, 26-44. doi: 10.1016/j.mad.2014.03.004

Tobin, D. J. (2015). Age-related hair pigment loss. Curr. Probl. Dermatol. 47, 128-138. doi: 10.1159/000369413

Tran, S., and Rizos, H. (2013). Human nevi lack distinguishing senescence traits. Aging 5, 98-99. doi: 10.18632/aging.100537

Tschachler, E., and Eckhart, L. (2017). Autophagy - how to control your intracellular diet. Br. J. Dermatol. 176, 1417-1419. doi: 10.1111/bjd.15566

Velarde, M. C. (2017). Epidermal barrier protects against age-associated systemic inflammation. J. Invest. Dermatol. 137, 1206-1208. doi: 10.1016/j.jid.2017. 02.964

Waldera-Lupa, D. M., Kalfalah, F., Florea, A. M., Sass, S., Kruse, F., Rieder, V., et al. (2014). Proteome-wide analysis reveals an age-associated cellular phenotype of in situ aged human fibroblasts. Aging 6, 56-78. doi: 10.18632/aging. 100698

Wang, A. S., and Dreesen, O. (2018). Biomarkers of cellular senescence and skin aging. Front. Genet. 9:247. doi: 10.3389/fgene.2018. 00247

Wang, Q., Bu, S., Xin, D., Li, B., Wang, L., and Lai, D. (2018). Autophagy is indispensable for the self-renewal and quiescence of ovarian cancer spheroid cells with stem cell-like properties. Oxid. Med. Cell. Longev. 2018:7010472. doi: $10.1155 / 2018 / 7010472$

Yaar, M., and Gilchrest, B. A. (1998). Aging versus photoaging: postulated mechanisms and effectors. J. Investig. Dermatol. Symp. Proc. 3, 47-51. doi: 10.1038/jidsymp.1998.12

Yaar, M., and Gilchrest, B. A. (2001). Ageing and photoageing of keratinocytes and melanocytes. Clin. Exp. Dermatol. 26, 583-591. doi: 10.1046/j.1365-2230.2001. 00895.x

Yang, F., Yang, L., Wataya-Kaneda, M., Hasegawa, J., Yoshimori, T., Tanemura, A., et al. (2018). Dysregulation of autophagy in melanocytes contributes to hypopigmented macules in tuberous sclerosis complex. J. Dermatol. Sci. 89, 155-164. doi: 10.1016/j.jdermsci.2017.11.002

Yoshihara, N., Ueno, T., Takagi, A., Oliva Trejo, J. A., Haruna, K., Suga, Y., et al. (2015). The significant role of autophagy in the granular layer in normal skin differentiation and hair growth. Arch. Dermatol. Res. 307, 159-169. doi: 10.1007/s00403-014-1508-0

Zalaudek, I., Grinschgl, S., Argenziano, G., Marghoob, A. A., Blum, A., Richtig E., et al. (2006). Age-related prevalence of dermoscopy patterns in acquired melanocytic naevi. Br. J. Dermatol. 154, 299-304. doi: 10.1111/j.1365-2133. 2005.06973.x

Zhang, C. F., Gruber, F., Ni, C., Mildner, M., Koenig, U., Karner, S., et al. (2015). Suppression of autophagy dysregulates the antioxidant response and causes premature senescence of melanocytes. J. Invest. Dermatol. 135, 1348-1357. doi: 10.1038/jid.2014.439

Zhao, Y., Zhang, C. F., Rossiter, H., Eckhart, L., König, U., Karner, S., et al. (2013). Autophagy is induced by UVA and promotes removal of oxidized phospholipids and protein aggregates in epidermal keratinocytes. J. Invest. Dermatol. 133 , 1629-1637. doi: 10.1038/jid.2013.26

Conflict of Interest Statement: The authors declare that the research was conducted in the absence of any commercial or financial relationships that could be construed as a potential conflict of interest.

Copyright (C) 2019 Eckhart, Tschachler and Gruber. This is an open-access article distributed under the terms of the Creative Commons Attribution License (CC BY). The use, distribution or reproduction in other forums is permitted, provided the original author(s) and the copyright owner(s) are credited and that the original publication in this journal is cited, in accordance with accepted academic practice. No use, distribution or reproduction is permitted which does not comply with these terms. 